Vittalle - Revista de Ciências da Saúde v. 30, n. 1 (2018) 115-129
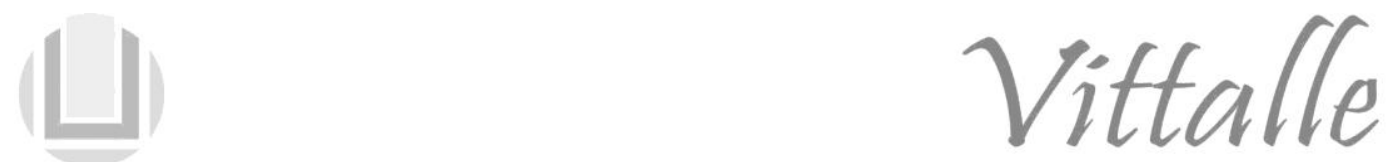

\title{
O vitalismo das Práticas Integrativas e Complementares e o conceito de campo da ciência moderna
}

\author{
Isa Paula Hamouche Abreu*
}

Secretaria de Estado de Saúde do Distrito Federal, Brasília, DF, Brasil

Curso de Homeopatia do Instituto de Saúde Integral de Brasília, Brasília, DF, Brasil

\section{Histórico do Artigo}

Recebido em:

15/11/2017

Aceito em:

09/04/2018

\section{Palavras-chave}

Vitalismo;

holismo e saúde; teoria de campo.

\section{Keywords}

Vitalism;

holism and health; field theory.

\begin{abstract}
RESUMO
As Práticas Integrativas e Complementares (PICs) abrangem procedimentos de sistemas médicos complexos (que possuem sua própria racionalidade médica) e recursos terapêuticos, integrativos e vitalistas. São indicadas como terapêutica complementar ou principal em diversas condições clínicas e nosológicas. Entretanto, essas práticas terapêuticas permanecem marginalizadas perante a racionalidade científica vigente, por estarem fundamentadas em paradigmas pouco ortodoxos, que desafiam o pensamento cartesiano-mecanicista ainda predominante. As PICs, de um modo geral, estão embasadas em uma concepção holística e vitalista, compreendendo o ser humano como uma unidade físico-energética/psicofísica, mental e espiritual, apresentando, portanto, uma dimensão material (corpo) e uma dimensão imaterial, sutil, que não pode ser apreendida pelos cinco sentidos. Por sua vez, a influência do pensamento cartesiano-mecanicista, no campo das ciências da saúde, resultou no chamado modelo biomédico, que se caracteriza pela dicotomia corpo-mente, pelo enfoque na doença e não na pessoa doente, pelo emprego exclusivo do método analítico, ou seja, da parte sem consideração da totalidade e do contexto, em síntese, pelo reducionismo e fragmentação em detrimento de uma visão sistêmica e integral. Todavia, os avanços da ciência moderna, particularmente nos campos da física e da psicologia, provocaram um rompimento com as ideias tradicionais a respeito do universo, da matéria e do ser humano. Este artigo tem por objetivo demonstrar que muitos avanços e teorias científicas da modernidade podem auxiliar na compreensão das PICs, enfocando, particularmente, as conexões da teoria vitalista com o eletromagnetismo e a teoria de campo.
\end{abstract}

The vitalism of Integrative and Complementary Practices and the field concept of modern science

\section{ABSTRACT}

Integrative and Complementary Practices (ICPs) encompass procedures with complex medical systems (which have their own medical rationality) and therapeutic, integrative and vitalist resources. They are indicated as complementary or main therapy in various clinical and nosological conditions. However, these therapeutic practices remain marginalized in the face of current scientific rationality, because they are based on unorthodox paradigms that challenge the still predominant Cartesian-mechanistic thinking. ICPs, in general, are based on a holistic and vitalist conception, comprising the human being as a physical-energetic / psychophysical, mental and spiritual unit, thus presenting a material dimension (body) and a subtle, immaterial dimension, which can not be grasped by the five senses. In turn, the influence of Cartesianmechanistic thinking in the field of health sciences has resulted in the so-called biomedical model, which is characterized by the body-mind dichotomy, by the focus on the disease rather than on the sick individual, by the exclusive use of the analytical method, or either from the part without consideration of the whole individual and the context, in synthesis, by reductionism and fragmentation to the detriment of a systemic and integral vision. However, advances in modern science, particularly in the fields of physics and psychology, have caused a rupture with traditional ideas about the universe, the matter, and the human being. This article aims to demonstrate that many of the advances and scientific theories of modernity can support the understanding of ICPs, with a particular focus on the connections of the vitalist theory with electromagnetism and field theory.

\footnotetext{
*Autor correspondente: isahamouche@gmail.com
} 


\section{Introdução}

$\mathrm{Na}$ atualidade, estamos vivendo uma profunda crise na saúde e na medicina, em particular. O paradigma materialista e mecanicista, ainda predominante no pensamento científico, embora tenha contribuído para um progresso tecnológico sem precedentes, não favorece ao desenvolvimento harmônico do ser humano em sua interação consigo mesmo, com o meio social e com a natureza.

As práticas de saúde contemporâneas vêm encontrando sérias limitações para responder efetivamente às complexas necessidades de saúde de indivíduos e populações. Três quartos da população mundial carecem de saúde, seja no sentido mais amplo, de condições coletivas adequadas e salubres de existência, seja no sentido mais estrito, de pessoas atingidas individualmente em seus sistemas psicofísicos $(1,2)$.

Além disso, essas práticas têm se mostrado extremamente iatrogênicas, invasivas, de custo elevado, desumanas, distantes, frias, indiferentes, muito mecânicas e tecnicistas, com tendência medicalizante, medicocêntrica, hospitalocêntrica, com o uso abusivo e irracional de tecnologias pesadas, e, ainda, voltadas para as doenças e não para o sujeito doente $(3,4)$.

A iatrogenia clínica, relativa aos danos causados nas pessoas pelos médicos, em função do excesso de intervenção e medicalização, tanto diagnóstica quanto terapêutica, vem ganhando dimensão coletiva e populacional, tornando-se recentemente a terceira maior causa de morte nos Estados Unidos da América, depois das doenças cardiovasculares e do câncer, conforme destacam Norman e Tesser (5), no artigo: Prevenção quaternária na atenção primária à saúde: uma necessidade do Sistema Único de Saúde.

Para exemplificar uma das manifestações dessa crise na saúde, desenvolve-se, atualmente, no mundo capitalista, um estado de "mal-estar", uma espécie de síndrome coletiva que se poderia definir como biopsíquica, com grande repercussão na saúde física e mental da força de trabalho, que atinge milhões de indivíduos das populações de quase todos os países nas grandes cidades, ocasionando uma situação permanente de sofrimento para os cidadãos e de perda de muitos milhões de dólares anuais para as economias desses países, em função de dias perdidos de trabalho (1).

A crise na saúde está ligada a uma crise socioeconômica e cultural muito mais ampla: uma complexa crise multidimensional, cujas facetas afetam todos os aspectos da nossa vida $(1,3)$.

Segundo Thomas Kuhn, as crises são uma pré-condição necessária para a emergência de novas teorias (7). É precisamente nesse contexto de crise na saúde que vem ocorrendo o crescimento, nas sociedades ocidentais, da busca e do uso dos sistemas terapêuticos comumente denominados "medicinas alternativas", entre os quais se incluem não apenas as medicinas tradicionais das culturas nacionais (ou mesmo regionais) como também as medicinas tradicionais provindas do Oriente: a medicina homeopática e a medicina antroposófica (1).

Estes sistemas terapêuticos têm o potencial de contribuírem para a elaboração de um novo paradigma nas ciências da saúde, por estarem impregnados de uma visão de integralidade, de unidade físico/energética, que leva em consideração, além do corpo físico, outras dimensões mais sutis do ser humano e a sua conexão com o universo a sua volta. Este novo paradigma, em seus traços gerais, seria marcado por uma abordagem terapêutica transdisciplinar e holística, e pelo desenvolvimento de um pensamento complexo, não linear, não reducionista $(8,9)$.

Todavia, distorções e desinformação sobre as PICs são previsíveis porque estes sistemas terapêuticos não se enquadram na racionalidade médica ainda predominante e, 
além disso, constituem-se uma ameaça aos interesses econômicos da poderosa indústria farmacêutica que tem grande influência na assistência à saúde (1.6).

Conforme assinala Luz (10), a ciência continua sendo o modo de produção de verdades socialmente dominantes, a teologia de nossa época. Desqualifica-se, então, nesse contexto, outras fontes de conhecimento, como, por exemplo, as oriundas de diferentes tradições filosófico-espirituais.

É importante considerar, nesta reflexão, que existe um processo de manipulação dos dados de estudos científicos, a fim de favorecer as intenções comerciais da indústria farmacêutica e, ainda, a corrupção das revistas científicas, que recebem recursos financeiros da indústria farmacêutica para publicarem os estudos científicos mais interessantes aos propósitos da indústria (6).

Por sua vez, é importante assinalar que, no universo desvelado pelos avanços da ciência moderna, particularmente nos campos da física e da psicologia, podem encontrar acolhida os pensamentos não ortodoxos das PICs. Os avanços da ciência moderna, com as suas descobertas, voltaram a evidenciar o pensamento existente desde a Antiguidade, o da inter-relação entre todas as coisas e eventos, constituindo-se o universo como um todo dinâmico e inseparável $(8,9)$.

Segundo o físico Fritjof Capra (11), nas três primeiras décadas do século XX, transformou-se, radicalmente, toda a situação da física. Dois desenvolvimentos separados - o da teoria da relatividade e o da física atômica (teoria quântica), que se constituem os fundamentos da física moderna - esfacelaram os principais conceitos da visão newtoniana-cartesiana do mundo: a noção de tempo e espaço absolutos e independentes, a matéria constituída de partículas sólidas elementares e indestrutíveis, o determinismo, a separação entre mente/corpo, sujeito/objeto, observador/observado e o ideal de uma descrição objetiva da natureza, independente dos nossos valores e crenças.

Entre os principais aspectos-chave evidenciados pela nova física, encontram-se:

1 - A energia - qualquer que seja - é irradiada ou absorvida pela matéria comum em quantidades mínimas, que Max Planck batizou de quantum, ou seja, Planck descobriu que a energia é absorvida e emitida em pequenos pedaços de forma descontínua. A partir desta constatação, foi deflagrada a revolução quântica que dura até hoje.

2 - Conforme afirmou Einstein, na sua teoria da relatividade especial, o espaço não é absoluto nem tridimensional, e o tempo não é absoluto, nem linear; espaço e tempo estão entrelaçados e fazem parte de um continuum quadridimensional denominado continuum espaço-tempo (11).

3 - A consequência mais importante da modificação da concepção sobre espaço e tempo é a compreensão de que a massa nada mais é que uma forma de energia. Mesmo um objeto em repouso possui energia armazenada em sua massa. Dessa maneira, massa e energia podem ser convertidas entre si. A equivalência entre massa e energia está expressa na famosa equação de Einstein $\mathbf{E}=\mathbf{m} \cdot \mathbf{c}^{2}$ (a quantidade de energia contida numa partícula é igual à massa da partícula, $m$, multiplicada por $c^{2}$, o quadrado da velocidade da luz). Para o médico Richard Gerber (12), o reconhecimento de que a matéria é uma forma de energia pode servir de base para a ideia de que os seres humanos podem ser considerados sistemas energéticos multidimensionais dinâmicos que se influenciam reciprocamente.

4 - As partículas elementares que constituem a matéria (como os elétrons, por exemplo, entre outras), a luz e outras formas eletromagnéticas têm um comportamento dual - a propriedade da dualidade onda-partícula. Ora se 
comportam como se fossem constituídas por partículas, ou seja, por elementos de massa confinada a um volume bem definido numa região específica do espaço, ora agem como se fossem ondas que se expandem em todas as direções. No nível atômico, a matéria e a luz tem um aspecto dual, manifestando-se como partícula e como onda. $\mathrm{O}$ aspecto que apresenta depende da situação. Essa propriedade dos elementos subatômicos contrapõe-se ao princípio da não contradição da lógica formal, que se encontra na base do racionalismo clássico. Aqui, estamos diante de uma nova lógica em que A é A e, também, A é não A. O físico quântico Niels Bohr, que se encontra na primeira geração de físicos que desenvolveram a teoria quântica, descreveu uma maneira nova de estudar o paradoxo da dualidade ondapartícula, elaborando o princípio da complementaridade. Segundo esse princípio, a natureza de onda e partícula do elétron não se refere a polaridades opostas. A representação como partícula e a representação como onda são duas descrições complementares da mesma realidade. Cada representação é necessária para que se obtenha uma descrição integral da realidade atômica. De acordo com Abreu $(8,9)$, a propriedade quântica da dualidade onda-partícula e o princípio da complementaridade tiram da obscuridade a teoria do Yin e do Yang, um dos pilares filosóficos da medicina tradicional chinesa.

5 - Ao observarmos um sistema físico, influenciamos seu comportamento; não existe mais uma separação clara entre observador e observado; na dimensão atômica, portanto, o observador não tem um papel passivo na descrição dos fenômenos naturais; em outras palavras, no mundo quântico, o observador tem um papel fundamental na determinação da natureza física do que está sendo observado; de certo modo, a realidade física observada é resultado de nossa escolha. Para o médico Larry Dossey (13): "Nenhum aspecto da física quântica foi mais revolucionário do que o reconhecimento que fez dos aspectos subjetivos do mundo". Foi o físico quântico Werner Heisenberg, um dos elaboradores da teoria quântica, quem introduziu esse papel crucial do observador na física quântica. De acordo com ele, não é possível falar sobre a natureza sem falar, ao mesmo tempo, sobre nós mesmos (11).

6 - A nossa linguagem ordinária é limitada para descrever a realidade quântica; a limitação da nossa linguagem se dá pela nossa percepção bipolar do mundo.

7 - A presença de matéria deforma a geometria do espaço e altera o fluxo do tempo. A força da gravidade, portanto, segundo a teoria da relatividade geral de Einstein, possui o efeito de "curvar" espaço e tempo (11).

8 - O princípio da incerteza, elaborado por Werner Heisenberg, segundo o qual, em nível subatômico, não podemos afirmar que exista matéria em lugares definidos do espaço, mas que existem "tendências a existir", e os eventos têm "tendências a ocorrer". Ou seja, devemos abandonar uma descrição estritamente determinista dos fenômenos naturais, pelo menos na escala atômica. A física, portanto, deixa de ser determinística para se tornar probabilística e o mundo de sólidos objetos materiais, da mecânica clássica, que se pensava bem definido, dissolve-se num complexo modelo de ondas de probabilidades (11).

9 - Todas as partículas subatômicas, logo, todos os átomos têm uma frequência vibratória própria, e essa onda vibratória foi batizada de onda piloto da matéria.

10 - A propriedade da não localidade ou do entrelaçamento ou da não separatividade, segundo a qual duas partículas que interagem continuam a influenciar e a transferir informação mútua e instantaneamente, não importando quão distante estejam uma da outra. Dessa forma, a não localidade é uma influência ou comunicação instantânea, sem qualquer troca de sinais através do espaço-tempo; ou seja, uma 
totalidade intacta ou não separatividade que transcende o espaço-tempo. Esse fenômeno é chamado de não localizado, porque a ideia de alguma coisa ser localizada significa que ela não é distante, e, no emaranhamento quântico, parece não se aplicar o conceito de distância. Tudo está se tocando o tempo todo. Essas conexões não locais são concebidas por alguns físicos como a própria essência da realidade quântica. Essa propriedade foi demonstrada em condições de laboratório para partículas (experimentos de Aspect e de Gisin), bem como entre seres humanos, por meio de sinais cerebrais (experimento de Grinberg-Zylberbaum). Segundo o físico Liimaa (14): "Com a comprovação da não localidade quântica, a medicina mente-corpo ganha um poderoso aliado no campo da ciência para ultrapassar a barreira mecanicista e reducionista da medicina materialista e medicamentosa...”. A propriedade da não-localidade quântica pode ajudar a compreender muitos processos de cura à distância, seja por preces intercessórias, seja por processos de visualização e meditação, pelo reiki ou por passes entre outros recursos. Há, hoje, evidências científicas de enorme amplitude e em número cada vez maior de que nossa mente também está conectada numa base não local Os dados acumulados a respeito de efeitos psíquicos, tais como a conexão telepática e a visão remota apoiam essa ideia. A propriedade da não localidade das entidades quânticas nos mostra que o universo é, inerentemente, uma totalidade (15).

A nova imagem da matéria, do universo e do ser humano, propiciada pelas revoluções da física moderna e da psicologia, abriu espaço para que a consciência e a dimensão subjetiva fossem reconduzidas ao cenário científico, aspectos esses que são centrais nas PICs.

Quando nos propomos a refletir sobre o papel da consciência na criação da realidade, colocamo-nos diante do famoso "problema quântico da medição", também conhecido como "o problema da observação". Atualmente, dentro da física, o problema da participação da consciência na formação da realidade é um dos mais centrais.

Segundo os físicos Rosenblum e Kuttner, autores do livro O enigma quântico: o encontro da física com a consciência (16):

\footnotetext{
A mecânica quântica tem um sucesso impressionante. Nem uma única previsão da teoria jamais esteve errada. Um terço da nossa economia depende de produtos baseados nela. No entanto, a mecânica quântica também exibe um enigma. Ela nos diz que a realidade física é criada pela observação, e que tem "ações fantasmagóricas" que influenciam instantaneamente eventos distantes entre si - sem nenhuma força física envolvida. Vista da perspectiva humana, a mecânica quântica é a física encontrando a consciência (ROSENBLUM; KUTTNER, 2017, p. 9).
}

Antes de observarmos ou medirmos uma partícula, ela existe como onda de probabilidade (função de onda). Ela não tem localização ou velocidade definida. Ela tem posições em potencial, velocidades em potencial - mas não saberemos quais são elas até que as observemos. Não há um consenso, entre os físicos, sobre a maneira como acontece essa transição de muitas realidades em potencial para uma única realidade. Muitos físicos já afirmaram que isso tem algo a ver com a consciência do observador, uma vez que é o ato da observação que leva a natureza a se decidir (17)

No que se refere à consciência, existem muitas questões ainda por serem elucidadas pela ciência. Será a consciência um produto do cérebro (uma visão materialista da consciência) ou é um componente fundamental do universo, independentemente do cérebro (que seria uma visão idealista da consciência)? Se levarmos em consideração esta última hipótese, poderíamos encontrar explicação para as milhares de experiências 
extracorpóreas ou de quase morte bem documentadas (18).

As principais tradições filosófico-religiosas da Antiguidade afirmaram, de uma forma ou de outra, que a consciência é o fundamental e que a energia - matéria é um produto da consciência. O materialismo, entretanto, ainda é dominante nos dias de hoje (18).

Um dos pioneiros da moderna pesquisa do cérebro, o neurocirurgião Wilder Penfield, quase no fim da vida, afirmou que, como neurocirurgião, acreditava que a consciência não se originava do cérebro. Pesquisas posteriores, e particularmente a tanatologia em seus estudos sobre as experiências quase-morte, acrescentaram evidência convincente à posição de Penfield (19).

Particularmente, na concepção do físico quântico Amit Goswami (20), a medicina mente-corpo só faz sentido quando se compreende que ela não é uma consequência da mente acima do corpo, mas uma consequência da consciência acima do corpo. Tanto o corpo quanto a mente são possibilidades quânticas da consciência. Essa concepção aceita e inclui a redescoberta da causação descendente na física quântica. A causação descendente é a consciência atuando causalmente sobre a matéria, ou seja, a consciência acima da matéria.

Em 1989, o médico endocrinologista e ayurvédico Deepak Chopra publicou um livro intitulado Cura quântica (21), no qual recorre ao pensamento quântico para explicar alguns casos de cura mente-corpo que se assemelham à autocura, pacientes curando a si mesmos.

No livro de Chopra (21), ele refere que, em sua carreira médica, por várias vezes, teve o privilégio de presenciar curas miraculosas. Ele relata vários casos de curas espontâneas e assinala que:

As pesquisas de curas espontâneas de câncer realizadas tanto nos Estados Unidos como no Japão demonstraram que, pouco antes do restabelecimento, quase todos os pacientes passam por uma alteração de consciência (CHOPRA, 1989, p. 27).

Chopra introduz o termo cura quântica para explicar as "curas milagrosas". Para ele, o mergulho em um grau mais profundo de consciência parece ser a chave para entender o mecanismo de tais curas (21).

Exercícios contemplativos como a meditação e o yoga, desenvolvidos por algumas tradições, que podem fortalecer os circuitos neurológicos relacionados à consciência, empatia e percepção social, têm atraído a atenção do Ocidente, tornando-se cada vez mais populares nas últimas décadas. Além disso, têm produzido um crescente interesse de grandes centros de pesquisa do mundo, principalmente na área da saúde (22).

$\mathrm{Na}$ primeira década do século XXI, os avanços da neurociência revolucionaram a maneira de pensarmos o cérebro. Em lugar de enxergá-lo como um órgão que amadurece lentamente durante as primeiras duas décadas de vida e depois diminui quando envelhecemos, os cientistas agora o veem como uma massa em constante mudança (23).

Desde a década de 1980, uma série de experimentos levados a efeito por Michael M. Merzennich mostrou que o cérebro se molda pela experiência. Hoje, está comprovado que, quando se muda um comportamento, uma forma de pensar, ou quando se exercita o aprendizado de coisas novas, o cérebro se modifica em função disso, independentemente da idade do indivíduo (24).

A neuroplasticidade refere-se à capacidade de o sistema nervoso alterar algumas propriedades morfológicas e funcionais em resposta a alterações do ambiente, é a adaptação e reorganização da dinâmica do sistema nervoso diante das alterações.

Os neurocientistas vêm estudando a eficácia da meditação como ferramenta para 
mudar profundamente as pessoas, inclusive suas formas de pensar. De acordo com Chopra (25): "Somos as únicas criaturas na face da terra capazes de mudar nossa biologia pelo que pensamos e sentimos".

Buda dizia: "Tudo o que somos é resultado do que pensamos. A mente é tudo. Nós nos tornamos aquilo que pensamos" (24).

Segundo Fernando A. C. Bignardi (26), médico, gerontólogo, psicoterapeuta, homeopata, coordenador do Centro de Estudos do Envelhecimento da UNIFESP (Universidade Federal de São Paulo), o estilo de vida e as escolhas cotidianas se convertem em doenças crônicas, como revelam as pesquisas epidemiológicas sobre o envelhecimento. Para ele, práticas meditativas, com raízes nas tradições orientais, constituem-se em uma ferramenta eficaz para intervir neste quadro.

As práticas meditativas são eficazes para atuar sobre a multidimensionalidade do praticante (dimensões física, emocional, mental, interpessoal e espiritual) e promovem mudanças positivas no indivíduo, que passa a desfrutar não só de uma nova condição de saúde mas de uma compreensão mais ampliada sobre os desafios e dificuldades impostos pela vida, bem como sobre a razão existencial do ser $(26,27,28,29)$.

Entre as décadas de 50 e 60, estudos pioneiros foram conduzidos com base em hipóteses de que as emoções poderiam afetar a evolução de doenças infecciosas. Esses estudos foram de fundamental importância para $o$ surgimento da psiconeuroendocrinoimunologia - ciência que investiga a influência das emoções nas interações entre os sistemas adaptativos (imunoneuroendócrino), e o papel de intervenções terapêuticas envolvendo mente-corpo para a manutenção do equilíbrio entre esses três sistemas e para a promoção e recuperação da saúde $(27,28,29)$.

Em seu artigo (26): A atitude transdisciplinar aplicada à saúde e sustentabilidade, uma abordagem multidimensional: a importância da meditação., Bignardi apresenta um ensaio clínico realizado em 2010/2011, com cerca de 140 idosos do bairro de São Matheus (periferia da cidade de São Paulo), no qual os participantes voluntários foram treinados em meditação. Nesse ensaio clínico, foi possível observar que os efeitos registrados seguiam a cascata de causalidade descendente, partindo da dimensão mais sutil (mental/psiquismo) para a mais densa (física).

No ensaio clínico citado acima, observou-se, de forma estatisticamente significativa, entre os participantes, melhora da memória, do humor, da postura física, que se tornou mais ereta, da respiração, do sono, do hábito intestinal, da disposição, do hábito alimentar, melhora clínica da dor e de doenças crônicas, como diabetes e hipertensão arterial sistêmica (26).

Por sua vez, Carlos Eduardo Tosta, médico, professor emérito e pesquisador sênior da área de imunologia da Faculdade de Medicina da UnB, propôs à coordenação de pósgraduação da Faculdade de Medicina uma nova linha de pesquisa científica: Impacto psiconeuroendocrinoimunológico da meditação prânica. A meditação prânica é uma modalidade de meditação sistematizada por ele, a partir dos ensinamentos do mestre indiano Baddhu Lari, e tem como base a antiga filosofia védica. Suas técnicas de respiração (pranayama) e visualização objetivam aquietar a mente e permitir a captação, concentração, circulação e projeção de prana para onde quer que se queira, seja uma parte doente de nosso corpo, seja para uma pessoa distante $(27,28,29)$.

O prana (na tradição indiana), que também recebe o nome de chi ou ch'i ou qi (na medicina tradicional chinesa) ou ki (na medicina tradicional japonesa), tem características que o distinguem das quatro forças ou energias reconhecidas pela ciência, existentes no universo, no atual estágio do conhecimento científico (2018): a eletromagnética, a gravitacional e as forças nucleares forte e fraca (energias encontradas nos núcleos dos átomos). Todas essas energias diminuem com a distância e são 
bloqueadas por barreiras, como a gaiola de Faraday, que impede a influência da energia eletromagnética. Diferentemente, o prana não é limitado pelo espaço-tempo e não é bloqueável pela matéria. E, mais surpreendentemente ainda, como afirma Tosta, o prana pode ser influenciado pela intenção $(27,28,29)$.

É consenso entre os físicos a convicção de que existe um grande número de modalidades energéticas ainda totalmente desconhecidas pela ciência (30). É oportuno lembrar que Albert Einstein, o grande gênio da ciência do século XX, enfatizou que as energias sutis (não físicas) são as formas de energia que ainda não podem ser medidas pelos equipamentos convencionais (mesmo pelos mais modernos, porque eles são, em essência, uma extensão dos cinco sentidos). Ele admitia a existência de "[...] formas sutis de energia que não podem ser medidas, mas que existem, logo são importantes" (24).

Para concluir essa breve apresentação dos aspectos mais relevantes da física moderna, da neurociência e dos estudos no campo da espiritualidade e saúde para as PICs, enfatizaremos que, na teoria da relatividade e na teoria quântica, a imagem do universo como uma máquina foi transcendida por uma visão dele como um todo dinâmico e indivisível, cujas partes estão essencialmente inter-relacionadas (11). No contexto desse novo pensamento, torna-se superficial e irracional qualquer abordagem em saúde que não considere a integralidade do ser e a sua relação com o ambiente no qual está inserido $(8,9)$.

Segundo Bohr (31), um dos formuladores da teoria quântica, como já referido acima, com a teoria da relatividade e a teoria quântica, a ciência ampliou a sua percepção sobre a natureza e a matéria e isso tem um alcance que ultrapassa em muito o campo particular da ciência física, sendo fundamental, portanto, que essa nova percepção seja incorporada cada vez mais à práxis científica e a todas as áreas do conhecimento.

O físico David Bohm lembra-nos que: "de forma instrutiva, é importante considerar que a palavra "saúde" encontra sua raiz na palavra "são", que significa "inteiro" (total, completo): isto é, para ser saudável é preciso estar inteiro..." (32).

O objetivo do presente trabalho é evidenciar que muitos avanços e teorias científicas da modernidade podem auxiliar na compreensão das PICs, focando especialmente as conexões da teoria vitalista com a teoria de campo da ciência moderna.

\section{A concepção vitalista}

$\mathrm{Na}$ história de todos os povos, em diferentes épocas, modernas e antigas, encontramos as concepções vitalistas, expressas de formas variadas, mas sempre propondo a existência de uma "força", de uma "energia", de um "corpo não material", de um "espírito", responsável pela existência, pelo metabolismo e pelo funcionamento dos seres vivos $(33,34)$.

O vitalismo é a doutrina que afirma a necessidade de um princípio irredutível ao domínio físico-químico para explicar os fenômenos vitais.

As escrituras das grandes religiões asiáticas, das primitivas religiões europeias e das diversas religiões pré-colombianas do hemisfério ocidental, por exemplo, afirmam que há algo além do corpo físico do ser humano. Durante séculos, clarividentes, escritores, assim como essas antigas filosofias e religiões se referiram a um corpo invisível que todos possuímos. Ele tem sido chamado, através dos séculos, "corpo sutil", "corpo astral", "corpo etérico", "corpo fluídico", "corpo equivalente", "corpo pré-físico", entre outras denominações (35).

Inúmeros místicos, ao longo da história, sempre afirmaram que os seres vivos em geral possuem uma espécie de halo energético, mais ou menos luminoso, envolvendo seus corpos. Para eles, esse halo luminoso (ou energético) é dinâmico, varia de cor, de 
intensidade e de tamanho, conforme o estado emocional e de saúde do seu possuidor. De acordo com esses relatos, as doenças manifestam-se primeiro na aura para depois se apresentarem no corpo físico ou material. Ainda segundo esses místicos, os minerais também são circundados por um halo energético, com a característica, porém, de que, nesse caso, o halo é estático, ou quase não sofre alterações (36).

Nas tradições da Antiguidade, em todas as partes do globo, encontramos, também, a proposição da existência de uma energia universal ou cósmica, vista como o constituinte básico e a origem de toda a vida, que compõe toda a matéria animada ou inanimada. $\mathrm{Na}$ tradição espiritual indiana, essa energia é denominada de prana; no taoísmo, é o qi; na cabala, é a luz astral; para os japoneses, é o ki; para os polinésios, é o mana; para os índios norte-americanos, é o orendo, por exemplo. Cabe assinalar como essa energia foi denominada por alguns pesquisadores ao longo do tempo, em diferentes épocas: Reichenbach a batizou de od, e Mesmer a chamou de "magnetismo animal". Já no século XX, Wilhelm Reich a denominou de "orgônio" e, na antiga União Soviética, V. Inyushin chamou-a de "bioplasma" (35).

Canguilhem (37), em seu livro $O$ normal e o patológico, afirma que, na história da medicina, o pensamento dos médicos oscilou entre duas representações fundamentais da doença: uma concepção organicista, localizante, mecanicista, no que se refere à causalidade, a qual ainda hoje é predominante, apesar das oscilações históricas das teorias médicas; e outra que é naturalista, na maioria das vezes vitalista.

$\mathrm{Na}$ história do vitalismo no Ocidente, cabe destacar Hipócrates (aproximadamente de 460 a 370 a.C.), Rhazes (865-925), Avicena (980-1037), Paracelso (1493-1541), Jacob Boehme (1575-1624), Van Helmont (1577-1644), George Ernst Stahl (1660-1734), Emmanuel Swedenborg (1688-1772), Paul Joseph Barthez (1734-1806) e a Escola de Montpelier, Franz Anton Mesmer (1734-1815), Karl von Reichenbach (1788-1869), Samuel Hahnemann (1755-1843), o qual fundamentou a homeopatia, Edward Bach (1886-1936), sistematizador da terapia floral e Rudolf Steiner (1861-1925) e Ita Wegman (1876-1943), que vão fundamentar a medicina antroposófica (38).

\section{A teoria eletromagnética e o conceito de campo}

Um dos conceitos-chave na física moderna, que, em muito, pode apoiar a concepção vitalista, é o conceito de campo. O conceito de campo é um conceito sutil e foi introduzido no final do século XIX por Michael Faraday (1791-1867) e James Clerk Maxwell (1831-1879) na descrição que fizeram das forças existentes entre cargas e correntes elétricas (11).

A mecânica newtoniana foi, por muito tempo, considerada a teoria final para a descrição dos fenômenos naturais, até o momento em que os fenômenos elétricos e magnéticos - que não dispunham de espaço na teoria de Newton - foram descobertos. A descoberta desses fenômenos, que não podiam ser adequadamente descritos pelo modelo mecanicista e envolviam um novo tipo de força, trouxe à tona as limitações do modelo newtoniano. Demonstrou que se tratava de um modelo incompleto, ou seja, que só podia ser aplicado a um grupo limitado de fenômenos, circunscritos ao universo macroscópico, perceptível pelos nossos cinco sentidos (11).

Faraday e Maxwell mostraram que a eletricidade e o magnetismo não eram forças separadas, e sim uma força que é hoje chamada de eletromagnética. Além disso, desenvolveram a ideia de um campo de força - conceito que está bem longe da ideia de que as forças estão relacionadas apenas com corpos materiais (11).

$\mathrm{Na}$ eletrodinâmica clássica, a teoria desenvolvida por Faraday e Maxwell, os campos são entendidos como entidades físicas primárias que podem ser estudadas sem qualquer 
referência aos corpos materiais. Os campos de vibração elétrica e magnética podem viajar através do espaço em forma de ondas de rádio, ondas de luz ou de outras espécies de radiação eletromagnética (11).

Albert Einstein propôs que poderíamos considerar a matéria como constituída por regiões do espaço nas quais o campo é extremamente intenso. Não há lugar nesse novo tipo de física para campo e matéria, pois o campo seria a única realidade (11).

Na teoria quântica dos campos, o contraste clássico entre as partículas sólidas e o espaço circunvizinho é completamente superado. O campo quantizado é concebido como entidade física fundamental, um meio contínuo que está presente em todos os pontos do espaço (11).

Dessa forma, todos os corpos, de uma forma ou de outra, criam campos em sua volta. No entanto, os corpos não utilizam para isso átomos, mas partículas virtuais - partículas criadas por flutuação de energia no vácuo quântico que possuem um tempo de vida extremamente pequeno. Essas partículas são denominadas virtuais por terem um tempo de vida extremamente pequeno, e não porque não tenham existência real (11).

Várias pesquisas científicas desenvolvidas a partir do século XX falam a favor da existência de um campo bioenergético que acompanha o corpo físico e contribui para a sua expressão funcional. Dessa forma, há uma espécie de retorno ao antigo conceito vitalista.

Poderíamos supor que o princípio vital e outras dimensões mais sutis do ser poderiam ser interpretadas como campos. Para alguns físicos, os campos de energia sutis atuam no domínio quântico, que atua além do espaço-tempo físico e de suas limitações (39).

No atual estágio da física teórica, portanto, a matéria não passa de uma minúscula onda num portentoso oceano de energia, embora dotada de relativa estabilidade e revestida de caráter manifesto.

No âmbito da cosmologia, foi feito o cálculo da composição atual do universo em $73 \%$ de energia escura (uma forma exótica de energia, que exerce força repulsiva, e que poderia explicar a expansão acelerada do universo que vem ocorrendo), $23 \%$ de matéria escura, opticamente invisível, e apenas 4\% de matéria normal ("bariônica"). Assim sendo, encontramo-nos mergulhados num mundo predominantemente imperceptível aos nossos sentidos comuns (40).

Entre as pesquisas e teorias em torno de um campo bioenergético, destacam-se:

1 - No início dos anos 1920, alguns biólogos compreenderam a necessidade de levantar a hipótese de uma estrutura de "campo" para explicar os vários processos biológicos. Hans Spemann, Alexander Gurwitsch e Pau Weiss, de maneira independente, haviam proposto a existência de "campos morfogenéticos" para explicar certas propriedades dos organismos em desenvolvimento. $\mathrm{O}$ conceito deriva do trabalho do biólogo Hans Driesch, o fundador do vitalismo moderno (41).

2 - Entre os mais sistemáticos pesquisadores da medição dos campos bioelétricos, encontram-se o neuroanatomista Harold Saxton Burr e o filósofo F. S. C. Northrop, da Universidade de Yale, nos EUA. Esses dois cientistas dedicaram cerca de 40 anos de pesquisas sérias e minuciosas à investigação de campos organizadores presentes nos meios biológicos. Em 1935, publicaram um livro intitulado Teoria eletrodinâmica da vida, onde relatavam os resultados de suas pesquisas. Utilizando instrumentos de medição elétrica muito sensíveis, concluíram que todo ser vivo, seja qual for sua natureza ou espécie, acha-se rodeado por um campo eletrodinâmico capaz de ser detectado por meio de voltímetros convencionais de alta sensibilidade. Batizaram esses novos campos energéticos de campos L (inicial da palavra life = vida, em inglês) ou campos de 
vida $(12,42,43)$. Entre as descobertas desses pesquisadores, encontra-se a constatação de que a mente consegue afetar e alterar o campo L da própria pessoa e também os de terceiros. Demonstraram que as emoções - e até mesmo a simples lembrança de fatos traumáticos e/ou felizes - alteram sensivelmente os campos L das pessoas - em primeiro lugar - para, em seguida, provocarem as devidas alterações bioquímicas e fisiológicas no corpo biológico. Observaram, ainda, que em um período de 24 horas, uma vez por mês, o campo L de qualquer mulher sofre uma substancial elevação de potencial energético, correspondente ao fenômeno da ovulação. Também foram descobertas correlações de variações dos campos L em relação às fases da Lua e ao ciclo solar de onze anos (manchas solares). A partir dessas constatações, ficou evidenciada a existência de uma estreita correlação entre o ser vivo e o meio circundante (o cosmos). As variações e/ou eventos cósmicos e ambientais afetam, de maneira bem sensível, os campos L dos seres vivos $(42,43)$.

3 - Em 1939, na cidade russa de Krasnodar, na antiga URSS, o engenheiro prático Semyon Davidovitch Kirlian redescobriu, acidentalmente, o que passou a ser conhecido como "efeito Kirlian" e inventou uma máquina que produzia um campo eletromagnético oscilatório de alta tensão e de alta frequência, capaz de fotografar um halo energético em torno dos corpos dos seres vivos. Quando um objeto qualquer, independentemente de ser orgânico ou inorgânico, era colocado em contato com esse campo, em torno desse objeto surgia uma espécie de halo luminoso de coloração variada, com predominância das cores branca, azul, vermelha, violeta, amarela e, algumas vezes, verde (46). Contando sempre com a colaboração de sua esposa, Valentina Khrisanovna Kirlian, ele passou a realizar diversos experimentos e a criar equipamentos, geralmente com peças rejeitadas pelos hospitais. O casal Kirlian publicou, em 1958, um relatório sobre suas experiências com fotografia eletrônica e as variações observadas nas imagens obtidas de acordo com diversos fatores, entre os quais eles incluíam as doenças e as alterações psicofísicas nas pessoas observadas (8,9). Em setembro de 1999, a Academia de Ciências da Rússia, durante a realização de um congresso em Moscou, considerou oficialmente a "kirliangrafia" um fato científico. Em 2000, o Ministério da Saúde da Rússia a recomendou para a prática médica (44).

4 - Uma teoria importante sobre os fenômenos energéticos sutis é a que vem sendo desenvolvida pelo engenheiro físico William A. Tiller. Ele elaborou um modelo teórico que chamou de modelo espaço-tempo positivo-negativo, que derivou da equação einsteiniana que estabelece a equivalência entre matéria e energia. Nesse modelo, na esfera do espaço-tempo positivo, também conhecido como universo do espaço-tempo físico, as energias e a matéria vibram em velocidades inferiores ou próximas às da luz e apresentam propriedades elétricas ou eletromagnéticas. Por sua vez, no universo do espaço-tempo negativo, encontram-se as partículas que se deslocam com velocidades maiores que as da luz e possuem propriedades magnéticas - diz-se que sua natureza é magnetoelétrica. Tiller teoriza que o espaço-tempo negativo é a esfera do etérico e de todas as dimensões mais sutis do ser humano, as quais correspondem a oitavas superiores de energia, que vibram numa velocidade maior que a da luz. Em sua perspectiva, os seres humanos são multidimensionais e há elementos de sua essência que residem no hiperespaço ou espaço superior. No seu modelo, o ser humano seria constituído pelos seguintes níveis: 1) nível biológico (químico); 2) nível eletromagnético; 3) nível etérico; 4) nível emocional; 5) nível mental; 6) nível espiritual $(12,45)$.

5 - Em 1981, o biólogo Rupert Sheldrake publicou seu primeiro livro intitulado A new 
Science of life (Uma nova ciência da vida), no qual apresenta sua teoria dos campos morfogenéticos, que parte de um conceito proposto desde a década de 1920. O termo "mórfico" provém do grego morphe, que significa "forma", e o termo genesis significa "vindo a ser". Segundo essa teoria, além dos campos energéticos conhecidos pela ciência, como o campo gravitacional e o eletromagnético, a natureza possui campos morfogenéticos, os quais são definidos pelo autor como invisíveis estruturas organizadoras, capazes de formar e organizar cristais, plantas e animais, determinando até o seu comportamento. Esses campos morfogenéticos contêm a soma de toda a história e de toda a evolução; seria algo semelhante ao conceito de Akasha dos antigos hindus ou ao inconsciente coletivo de C. G. Jung. Para Sheldrake, todos os seres têm um tipo de aura que os liga ao mundo circundante. Os campos mórficos de Sheldrake não envolvem transmissão de energia. $\mathrm{O}$ que se transmite por meio deles é pura informação. Juntamente com a ideia de campo morfogenético, ele elabora o conceito de ressonância mórfica. Com esse conceito, ele visava compreender como as informações ou padrões de atividade passam de um sistema antigo para um novo do mesmo gênero. Sheldrake chamou de ressonância mórfica a difusão não intencional da informação, o que difere da telepatia, que é intencional, associada a uma coletividade, seja humana ou não. A ressonância mórfica não é afetada pelo espaço ou pelo tempo, e sua influência aumenta à medida que cresce o grau de similaridade dos sistemas envolvidos $(46,47)$.

Muitos dos pesquisadores do biocampo aceitam a ideia de que esse biocampo é um campo organizador da vida global e que sua maneira de funcionar tem pontos de semelhança com a holografia: enquanto uma placa holográfica transmite informações por todo um holograma, o biocampo envia informações por todo o corpo. Além de controlar a fisiologia do organismo, ele tem um papel crucial na sua integração. No entanto, os estudiosos ainda não chegaram a um consenso sobre a constituição desse campo biológico: é certeza que ele envolve eletromagnetismo, mas pode incluir também campos adicionais, ainda não caracterizados $(12,15,18)$.

Nessa reflexão sobre o biocampo, é preciso acrescentar o aspecto da informação. A informação, em sua essência, não pode ser classificada nem como energia nem como matéria. Estas são simplesmente suas armazenadoras e transportadoras. A informação parece ser uma terceira propriedade da natureza (18).

Di Biase e Rocha (48) definem informação como: “[...] a propriedade intrínseca e irredutível do universo capaz de gerar ordem, auto-organização e complexidade.

\section{Considerações finais}

$\mathrm{Na}$ física, o paradigma mecanicista teve de ser abandonado no nível do muito pequeno (na física atômica e subatômica) e no nível do muito grande (na astrofísica e na cosmologia). Entretanto, na biologia e nas ciências da saúde ainda predomina a abordagem fragmentária e reducionista do modelo cartesiano-mecanicista, que, há mais de 100 anos, já demonstrou ser um modelo impreciso da realidade (49).

Considerando o indivíduo na sua dimensão global - sem perder de vista a sua singularidade, quando da explicação de seus processos de adoecimento e de saúde -, as PICs corroboram para a integralidade da atenção à saúde.

Entretanto, essas práticas despertam questionamentos e ceticismo na classe científica, acostumada ao paradigma cartesiano-mecanicista. Por isso, são frequentemente tachadas de anticientíficas, "místicas", "esotéricas", com vistas à sua desqualificação. Tais 
posicionamentos apoiam-se, certamente, em uma concepção estreita a qual sustenta que a única fonte produtora de conhecimento legítimo é a ciência.

As PICs foram engendradas por outras, por assim dizer, "racionalidades", diferentes da racionalidade científica predominante e essas práticas não contam, até o presente momento, com nenhuma teoria científica aceita que as justifiquem. Neste ponto, vale lembrar que, em ciência, como todos sabem, a demonstração de fatos empíricos, muitas vezes, precede o desenvolvimento de uma teoria explicativa (4).

Com este artigo, busco sensibilizar os profissionais de saúde para novas maneiras de pensar "além do casulo", ampliando a sua compreensão e a sua práxis a partir do aporte de diferentes campos de conhecimento, seja o da ciência, o das tradições sapienciais ou o das artes, o que se constituiria em uma abordagem transdisciplinar. Daí o propósito de investigar pontos de conexão entre as PICs e as teorias oriundas da ciência moderna, tendo sido enfocado neste manuscrito, particularmente, as possíveis conexões da concepção vitalista das PICs com a teoria de campo da ciência moderna.

Os preceitos filosóficos que embasam as PICs, de um modo geral, não divergem dos conhecimentos científicos atuais sobre o universo. O filósofo e sociólogo francês Edgar Morin, que é um dos principais pensadores da teoria da complexidade, admite que seja possível a existência de várias verdades simultâneas, aproximações de verdades que não se excluem mutuamente (50).

O conceito de campo da ciência moderna chama a nossa atenção para dimensões mais sutis da realidade. Einstein afirmou que (51): “...o campo é a única realidade”.

\section{Referências}

1. Luz MT. Novos saberes e práticas em saúde coletiva: estudo sobre racionalidades médicas e atividades corporais. 2 ed., revista. São Paulo: Editora Hucitec; 2005.

2. Ayres JRCM. O cuidado, os modos de ser (do) humano e as práticas de saúde. [Internet]. São Paulo: Saúde Soc. 2004; 13 (3): 16-29.

3. Capra F. Prefácio. In: Dossey, L. Espaço, tempo e medicina. Tradução de Paulo Cesar de Oliveira. São Paulo: Cultrix; 1998. p. 9-12.

4. Dossey L. A cura além do corpo: a medicina e o alcance infinito da mente. Tradução Gilson César Cardoso de Sousa. São Paulo: Editora Cultrix; 2004.

5. Norman AH, Tesser CD. Prevenção quaternária na atenção primária à saúde: uma necessidade do Sistema Único de Saúde. In: Cad. Saúde Pública 2009; 25 (9): 2012 - 2020.

6. Gotzsche PC. Medicamentos mortais e crime organizado: como a indústria farmacêutica corrompeu a assistência médica. Tradução Ananyr Porto Fajardo. Revisão técnica Daniel Knupp Augusto. Porto Alegre: Bookman; 2016.

7. Kunh TS. A estrutura das revoluções científicas. $9^{a}$ ed. São Paulo: Perspectiva; 2007.

8. Abreu IPH. A homeopatia e a ciência moderna: conexões. São Paulo: All Print Editora; 2016. (Coleção homeopatia: fundamentos históricos, conexões com a ciência moderna e o testemunho da clínica; v. 2).

9. Abreu IPH. Saúde integral: conexões com as tradições da Antiguidade e com a ciência moderna: a integralidade e o Sistema Único de Saúde do Brasil - SUS, volume 2. São Paulo: All Print Editora; 2015.

10. Luz MT. Natural, racional, social: razão médica e racionalidade científica moderna. Rio de Janeiro: Campus; 1988.

11. Capra F. O Tao da Física: um paralelo entre a física moderna e o misticismo oriental. Tradução de José Fernandes Dias. São Paulo: Cultrix; 1991.

12. Gerber R. Medicina vibracional: uma medicina para o futuro. São Paulo: Editora Cultrix; 1993.

13. Dossey L. Espaço, tempo e medicina. Tradução de Paulo Cesar de Oliveira. São Paulo: Cultrix; 1998.

14. Liimaa W. Medicina mente-corpo: uma abordagem quântica, relativística e ecológica. In: Liimaa, W 
(Org.). Pontos de mutação na saúde: integrando corpo e mente. São Paulo: Aleph; 2011. p. 27-54.

15. Laszlo E, Currivan J. Cosmos: unindo ciência e espiritualidade para um novo entendimento do universo e de nós mesmos. Tradução Aleph Teruya Eichemberg e Newton Roberval Eichemberg. São Paulo: Cultrix; 2010.

16. Rosenblum B, Kuttner F. O enigma quântico: o encontro da física com a consciência. Tradução George Schlesinger. Revisão técnica Alexandre Cherman. 1 ed. Rio de Janeiro: Zahar; 2017.

17. Davies P. Esse fluxo misterioso. In: Scientific American Brasil 2002; 1 (5): 54-59.

18. Laszlo E. A ciência e o campo Akáshico: uma teoria integral de tudo. Tradução Aleph Teruya Eichemberg e Newton Roberval Eichemberg. São Paulo; 2008.

19. Grof S, Bennett HZ. A mente holográfica: novos conhecimentos sobre psicologia e pesquisa da consciência. Tradução de Wanda de Oliveira Rosellli. Rio de Janeiro: Rocco; 1994.

20. Goswami A. O médico quântico: orientações de um físico para a saúde e a cura. Tradução de Euclides Luiz Calloni e Cleusa Margô Wosgrau. São Paulo: Cultriz; 2006.

21. Chopra D. A cura quântica: o poder da mente e da consciência na busca da saúde integral. Tradução Evelyn Kay Massaro e Marcília Britto. 2. ed. São Paulo: Best Seller; 1989.

22. Danucalov MAD, Simões RS. Neurofisiologia da meditação: investigação científica no yoga e nas experiências místico-religiosas: a união entre ciência e espiritualidade. São Paulo: Phorte; 2006.

23. Newberg A, Waldman MR. Como Deus pode mudar sua mente. Tradução Julio de Andrade Filho. São Paulo: Prumo; 2009.

24. Azevedo C. Órion: filosofia, religião e ciência: sobre o homem. v. 2. Rio de Janeiro: ABC Editora; 2005.

25. Chopra D. Corpo sem idade, mente sem fronteiras: a alternativa quântica para o envelhecimento. Tradução de Haroldo Netto. 10. ed. Rio de Janeiro: Rocco; 1999.

26. Bignardi FAC. A atitude transdisciplinar aplicada a saúde e sustentabilidade, uma abordagem multidimensional: a importância da meditação. Terceiro Incluído 2011; 1 (1): 14-24.

27. Tosta CE. Entrevista concedida por Carlos Eduardo Tosta à revista do Correio Braziliense. [Internet]. Brasília: Correio Braziliense; 2012. Disponível em: http://www.correiobraziliense.com.br/app/noticia/revista/2012/09/09/interna_revista_correio,321407/ espiritualidade-e-ciencia.shtml

28. Tosta CE. Vídeo com entrevista concedida pelo Prof. Carlos Eduardo Tosta à Mônica Nóbrega. [Internet]. Brasília; 2012. Disponível em: https://www.youtube.com/watch?v=t5YNVhlthsE

29. Silva CAF da. Efeitos da biometenergia de praticantes de meditação prânica sobre as dores crônicas de coluna vertebral. Brasília, 2016. Tese (Doutorado). Universidade de Brasília. Programa de PósGraduação em Ciências Médicas da Faculdade de Medicina. Área de Concentração: Ciências Aplicadas em Saúde. Orientador Prof. Dr. Carlos Eduardo Tosta. Disponível em: repositorio.unb.br/bitstream/10482/20139/1/2016_CesarAugustusFernandesSilva.pdf

30. Milhomens N. O misticismo à luz da ciência. São Paulo: IBRASA; 1997.

31. Bohr N. Física atômica e conhecimento humano: ensaios 1932-1957. Tradução Vera Ribeiro. Rio de Janeiro: Contraponto; 1995.

32. Bohm D. Totalidade e a Ordem Implicada. Tradução Teodoro Lorente. São Paulo: Madras; 2008.

33. Sabetti S. O princípio da totalidade: uma análise do processo da energia vital. Tradução de Zilda Schild. São Paulo: Summus; 1991.

34. Teixeira MZ. A natureza imaterial do homem: estudo comparativo do vitalismo homeopático com as principais concepções médicas e filosóficas. São Paulo: Petrus; 2000.

35. Ostrander S, Schroeder L. Experiências psíquicas além da cortina de ferro. Tradução de Octavio Mendes Cajado. 3 ed. São Paulo: Cultrix; 1970.

36. Milhomens N. Fotos Kirlian: como interpretar. 6 ed. ver. E ampl. São Paulo: IBRASA; 1988. (Biblioteca Parapsicologia, v. 9).

37. Canguilhem G. O normal e o patológico. Tradução de Maria Thereza Redig de Carvalho Barrocas e Luiz Octávio Ferreira Barreto Leite. 5 ed. ampl. Rio de Janeiro: Forence Universitária; 2002.

38. Abreu IPH. Saúde integral: conexões com as tradições da Antiguidade e com a ciência moderna: a marca da totalidade e do vitalismo, volume 1. São Paulo: All Print Editora; 2015. 
39. Lalarora H. As materializações à luz da física moderna. In: Weil, P. et al. Transcomunicação: o fenômeno Magenta: observações e interpretações de fenômenos paranormais ocorridos na presença do sensitivo Amyr Amiden. São Paulo: Pensamento; 2004. p. 169-172.

40. Makler M, Villela Neto T. Cosmologia: a busca pela origem, evolução e estrutura do universo. In: Anjos J, Vieira CL. (Eds.). Um olhar para o futuro: desafios da física para o século 21. Rio de Janeiro: Vieira \& Lent; 2008. p. 94-109.

41. Bischof M. Conceitos vitalista e mecanicista na história do bioeletromagnetismo. [Internet]. 2010. Disponível em: <http://www.marcobischof.com/en/texte/index.html>.

42. Milhomens N. O modelo energético do homem: uma hipótese de trabalho: o efeito Kirlian. São Paulo: IBRASA; 1988. (Biblioteca Parapsicologia, v. 8).

43. Milhomens N. Vida, universo e mente. São Paulo: IBRASA; 1995.

44. Milhomens N. Sobre a bioeletrografia. [Internet]. Brasil: IUMAB - International Union of Medical and Applied Bioelectrography in Brazil. Disponível em: http://www.bioeletrografia.com.

45. Tiller WA. Science and human transformation: subtle energies, intentionality and consciousness. Walnut Creek: Pavior Publishing; 1997.

46. Araia E. Rupert Sheldrake: teoria dos campos mórficos: uma ousadia científica. Revista Planeta 2005; 32 (395): 78-81.

47. Weber R. Diálogos com cientistas e sábios: a busca da unidade. São Paulo: Círculo do Livro; 1989.

48. Di Biase F, Rocha MSF. Informação, auto-organização e consciência: rumo a uma teoria holoinformacional da consciência. In: Di Biase F. O homem holístico: a unidade mente-natureza. Petrópolis: Vozes; 1995. p. 222-240.

49. Capra F. O ponto de mutação: a ciência, a sociedade e a cultura emergente. Tradução Álvaro Cabral. São Paulo: Cultrix; 1993.

50. Morin E. Introdução ao pensamento complexo. 3. ed. Porto Alegre: Editora Sulina; 2007.

51. Einstein A. A teoria da relatividade especial e geral. Tradução do original alemão Carlos Almeida Pereira. Rio de Janeiro: Contraponto; 1999. 